\title{
Os estudos sobre a Relação Família-Escola no Brasil: uma revisão sistemática
}

\author{
Studies on Family-School Relationship in Brazil: a systematic review
}

Los estudios sobre la Relación Familia-Escuela en Brasil: una revisión sistemática

\author{
LISIANE ALVIM SARAIVA-JUNGES* \\ ADRIANA WAGNER**
}

\begin{abstract}
$\longrightarrow$ \&
RESUMO

A Relação Família-Escola tem atraído interesse de muitos pesquisadores, pois quando bem estabelecida previne comportamentos disfuncionais. No Brasil, percebem-se algumas lacunas na abordagem desta temática, o que motivou a realização deste estudo. O objetivo deste trabalho, portanto, foi conhecer o estado da arte do tema "Relação Família-Escola" em nosso país a partir de uma revisão sistemática da literatura. O levantamento resultou em 31 artigos que foram analisados sob o ponto de vista metodológico e temático. Os artigos refletem a complexidade inerente à temática, assim como as metodologias disponíveis para aceder a ela. Alguns denotam certa dificuldade de delimitação do objeto de pesquisa. Conclui-se que a produção acadêmica sobre o tema no Brasil encontra-se em momento de diagnóstico de dificuldades e constatação da necessidade de propostas de intervenção para otimização, mas ainda não se percebem avanços quanto à proposições práticas que fomentem uma parceria efetiva entre escola e famílias.
\end{abstract}

Palavras-chave: Relação Família-Escola. Revisão sistemática. Literatura brasileira.

\begin{abstract}
Family-School Relationship has been attracting the interest of many researchers nowadays, as evidence shows that a well-established relationship predicts health index. In Brazil, some gaps are perceived when addressing this issue, which motivated the present study. The aim of this paper, therefore, was to know the state of the art of "Family-School Relationship" in our country, from a systematic literature review. The survey resulted in 31 articles that were analyzed from methodological and thematic perspectives. The articles reflected the inherent complexity of the topic, as well as the methods available to access it. Some studies denoted some difficulties in defining the object of research. It is concluded that the academic literature on the topic in Brazil is currently diagnosing the difficulties and pointing out the need of new intervention proposals for optimization, but there are no advances yet considering practical proposals to foster an effective partnership between school and families.
\end{abstract}

Keywords: Familly-School Relationship. Systematic review. Brasilian literature.

\section{RESUMEN}

La Relación Familia-Escuela ha atraído intereses de muchos investigadores actualmente, pues estas evidencias demuestran que esta relación, cuando bien establecida, es beneficiosa a la salud. En Brasil, existen vacíos en el conocimiento de esta temática, que motivó la realización de este estúdio. O objetivo deste estúdio, por lo tanto, era conocer el estado del arte de la "Relación Familia-Escuela" en nuestro país, a partir de una revisión sistemática de la literatura. Se encontraron 31 artículos en el levantamento, que fueron analizados sobre el punto de vista metodológico y temático. Los artículos parecen reflejar la complexidad inherente sobre la temática, así como las metodologías disponibles para acceder al problema. Algunos denotan con cierta dificultad la delimitación del objeto de investigación. La producción académica de este tema en Brasil se encuentra en un momento de diagnóstico de las dificultades y constatación de la necesidad de propuestas de intervención para la optimización, pero aún no se ven avanzos con la relación de propuestas prácticas que busquen trabajar en pro de una alianza entre escuelas y familias.

Palabras clave: Relación Familia-Escuela. Revisión sistemática. Literatura brasileña.

\footnotetext{
*Doutora em Psicologia, Universidade Federal do Rio Grande do Sul.E-mail:<lisianesaraiva@hotmail.com>.

**Doutora em Psicologia, Universidade Federal do Rio Grande do Sul.E-mail:<adrianaxwagner@gmail.com>.
} 


\section{INTRODUÇÃO}

A Família e a Escola são sistemas que dividem a tarefa de educar e socializar crianças e jovens. Nos últimos tempos, inúmeros pesquisadores, de diversas áreas do conhecimento, tem se dedicado a estudar e entender melhor a relação que se estabelece entre estes dois contextos (OLIVEIRA e MARINHO-ARAÚJO, 2010; FARIA FILHO, 2000), pois ainda que se mostre de suma importância, o campo de estudo que trata da parceria família-escola é relativamente novo se comparado a outras áreas da pesquisa em Educação (EPSTEIN, 2011). Tais estudos já evidenciaram que uma boa parceria entre família e escola funciona como fator preditor de saúde, melhorando o processo de aprendizagem e os resultados acadêmicos, prevenindo problemas de comportamento, faltas e abandono escolar e estimulando o seguimento dos estudos em nível superior (EPSTEIN, 2011; KOUTROUBA, ANTONOPOULOU, TSITSAN et al., 2009; POLONIA e DESSEN, 2005; XU, 2002; BHERING e SIRAJ-BLATCHFORD, 1999; CAVALCANTE, 1998).

Os últimos 25 anos, portanto, mostraram crescimento desta área de estudos, levando cada vez mais educadores e políticos a se interessarem sobre a temática (EPSTEIN, 2011). Nos Estados Unidos, por exemplo, já existem programas de intervenção consolidados que buscam qualificar cada vez mais esta relação. No Brasil, segundo Nogueira, Romanelli e Zago (2011), ainda não existe propriamente uma tradição de pesquisas sobre o tema das relações que as famílias mantêm com a escola. Citam como prova disso o fato de que ao longo das décadas de 80 e 90 apenas quatro números temáticos de periódicos científicos de circulação nacional da área da educação se dedicaram a abordar o assunto: em 1981, nos Cadernos de Pesquisa, o tema foi "A família em questão"; em 1992, no Psicologia USP, o tema foi "Família e Educação"; em 1994, nos Cadernos de Pesquisa, novamente, o tema foi "A família em Destaque"; e em 1997, no Caderno Cedes, o tema foi "Família, escola e sociedade". Entretanto, do total de 37 artigos publicados nestas edições, apenas três abordavam, de fato, a família em suas relações com a vida escolar dos filhos (NOGUEIRA, ROMANELLI e ZAGO, 2011). A produção discente de teses e dissertaçõesem Educação entre 1982-1991 apresenta apenas 1,77\% da produção total inserido no grupo "família e educação/ mulher".

Faz-se importante assinalar que sob a designação "relação família e escola", se abriga uma problemática extremamente ampla, multifacetada e passível de ser abordada por diversos campos disciplinares, tais como Antropologia, Psicologia Social e Escolar, Educação, Sociologia, entre outros. Se por um lado este fator é positivo, pois demonstra o interesse em se pensar e produzir conhecimento a respeito desta relevante temática, por outro, causa certa dispersão, dificultando o trabalho de organização e classificação da produção. Assim, ainda não há uma descrição do "estado da arte" das diversas tendências temáticas e teórico-metodológicas dos estudos que abordam as relações entre famílias e escolas e a educação escolar no Brasil (NOGUEIRA, ROMANELLI e ZAGO, 2011).

Tal falta de sistematização torna difícil a realização de uma avaliação clara sobre a importância e o lugar que a temática "família e escola" ocupa em nossa realidade. Baseada em investigações lideradas por seu grupo de pesquisa nos Estados Unidos e por parceiros sediados em diversos outros países, Epstein et al. (2009) concluíram que muitas situações se assemelham nos mais diversos contextos no que se refere à dinâmica da parceria famíliaescola. Assim, é fato que, independentemente do contexto cultural, os pais tendem a participar e se envolver das mais variadas formas com a escola dos seus filhos e demonstram preocupação com o sucesso dos mesmos na escola; os estudantes precisam de diversos recursos e apoio para auxiliá-los a serem bem sucedidos na escola; a escola deve liderar projetos que promovam o envolvimento de todas as famílias, sem exceções; alguns professores e administradores escolares são inicialmente resistentes para promover esta parceria e ultrapassar as barreiras e dificuldades iniciais; são necessários mecanismos que auxiliem os professores e a equipe escolar a fortalecer e, sobretudo, manter os programas de parceria com as famílias; os programas são mais efetivos quando baseados em evidências científicas, quando se adaptam a cada comunidade e quando são avaliados continuamente.

Ainda que muitas situações se assemelhem em diferentes contextos, Polonia e Dessen (2005) referem como fundamental a existência de dados empíricos nacionais que permitam identificar fatores que facilitam ou dificultam a interação família-escola, pois é apenas com base empírica que se poderá influenciar e estruturar as políticas educacionais. Há lacunas no conhecimento que se tem produzido em nosso país e, também, sobre quais são os principais métodos, amostras e instrumentos utilizados. Tão pouco estão claros quais os principais temas abordados e a partir de que perspectiva teórica os estudos tem sido realizados. Assim, este estudo pretende contribuir para o conhecimento do estado da arte da temática "Relação Família-Escola" em nosso país, a partir de uma revisão sistemática da literatura brasileira nas principais bases de dados que congregam artigos nacionais.

\section{MÉTOdo}

O levantamento dos artigos brasileiros ocorreu mediante busca nas bases de dados: Scielo, Pepsic, Index 
Psi e Lilacs e foi realizado a partir de três tentativas de descritores: as expressões "Relação Família-Escola", "Família e Escola" e "Parceria Família-Escola". Foram seguidos os procedimentos que garantissem que a busca delimitasse as publicações em periódicos brasileiros, ainda que a pesquisa pudesse ter sido realizada com sujeitos de outros países. Não foi delimitado um intervalo específico de busca considerando os anos das publicações, preferindo-se conhecer, primeiramente, resultados a partir das buscas atemporais.

Baseado nesses critérios, chegou-se inicialmente a 158 artigos, muitos dos quais se repetiam nas diferentes bases de dados. A leitura dos títulos e resumos permitiu excluir artigos que não tratavam propriamente do tema "Relação Família-Escola", apenas tangenciando-o.Após esta primeira seleção, restaram 32 publicações. A partir daí, todos os artigos foram lidos na íntegra e excluiu-se um que, embora mencionasse no resumo o tema "relações família-escola", versava sobre o atendimento familiar de orientação sistêmica relacionado à aprendizagem. As informações contidas nos demais 31 artigos foram organizadas em uma tabela com os seguintes itens: identificação dos autores e do periódico de publicação (título, ano, local, volume, número), local da realização da pesquisa (quando se tratasse de relato de pesquisa), objetivos, método, participantes, instrumentos, principais resultados/conclusões e observações do pesquisador.

\section{RESUltados}

A leitura na íntegra da coleção dos 31 artigos permitiu a organização de três grandes eixos de temáticos que serão apresentados e descritos a seguir.

\section{Eixo I - Aspectos metodológicos e estruturais}

\section{a) Características Gerais das Publicações e Componentes Estruturais dos Artigos}

A leitura dos 31 artigos permitiu verificar que 25 foram publicados em periódicos do estado de São Paulo, sendo as principais revistas de publicação "Cadernos de Pesquisa" (cinco artigos), "Paidéia" (cinco artigos), "Psicologia Escolar e Educacional" (quatro artigos) e "Estudos de Psicologia - Campinas" e "Psicologia da Educação" (ambas com três artigos). Todos os títulos acima se encontram entre as classificações A1 e B2, segundo critérios de avaliação do Qualis Periódicos da CAPES. Os demais doze artigos foram publicados em revistas do Distrito Federal (2), do Rio Grande do Sul (1), Rio de Janeiro (1), Minas Gerais (1) e Rio Grande do Norte (1). Estas revistas receberam Qualis que variaram de A1 a C. Um dado que chama a atenção é que dos 55 autores e coautores dos 31 artigos, 47 pertenciam ao sexo feminino, equivalendo a $85,45 \%$ do total. Isso nos remete ao fato da educação básica ser ainda um campo de atuação prioritariamente desempenhado por mulheres que, consequentemente, parecem ser as que mais publicam, teorizam e debatem tais temas.

Considerando que não houve delimitação do ano de publicação na busca, a distribuição dos artigos mostrou maior concentração no período compreendido entre 2004 e 2012 (61,3\%). Isso confirma o aumento do interesse pelo tema da Relação Família-Escola na atualidade, conforme salientou Epstein (2011) ao referir que o campo de estudo é relativamente novo se comparado a outras áreas de pesquisa. Tal crescimento pode ser observado no gráfico abaixo:

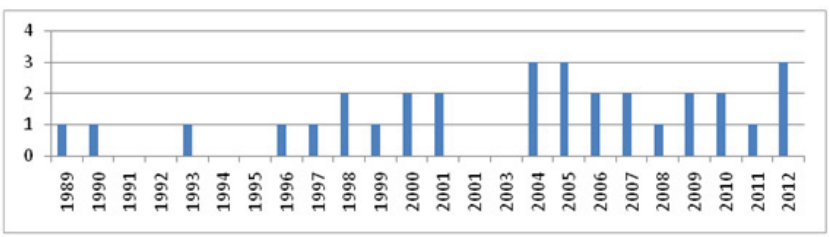

Figura 1. Distribuição das publicações por ano

Com relação aos tipos de trabalho, 14 artigos apresentavam resultados de pesquisa; 13 foram elaborados teoricamente, em forma de reflexão crítica da literatura, entre outras modalidades. Com relação à estrutura que deve ser obedecida na redação de um artigo (introdução, objetivos, método, participantes, instrumentos, análise de resultados e conclusão) foi possível constatar, no que tange aos objetivos traçados nos trabalhos, que dos 31 artigos analisados, 22 possuíam objetivos claramente definidos (doze destes eram artigos empíricos), enquanto quatro apresentavam objetivos pouco precisos, vagos. Os demais (cinco trabalhos) não mencionaram seus objetivos claramente.

No que se refere à descrição do método empregado, doze o fizeram de forma clara e compreensível ao leitor, sendo a maioria destes artigos empíricos. Dos demais 19, seis explicaram o método de forma confusa, incompleta ou sem delimitação. Outros 13 artigos não mencionaram método. Entre estes últimos, encontraramse fundamentalmente artigos que se auto intitulavam como "revisão de literatura", "relato de experiência", "revisão crítica da literatura", "reflexão", etc. Constata-se que pelo fato de serem trabalhos teóricos, parece haver certa tolerância a não descrição dos procedimentos adotados, especialmente os que tratam de uma revisão de literatura.

Dos 14 trabalhos empíricos, a maioria optou pelo método qualitativo para investigar o fenômeno (13), sendo que oito foram realizados em escolas públicas, cinco em escolas particulares e um não mencionou o perfil 
de escola. Com relação ao nível de ensino, dez foram realizados no contexto do ensino fundamental, seguidos por três na educação infantil e apenas um em creche e um em ensino médio. Os níveis socioeconômicos mais pesquisados foram o médio (quatro estudos) e o baixo (quatro estudos), seguidos por médio alto e médio baixo (estes últimos sendo investigados em dois estudos cada um). Chama atenção que seis estudos não mencionaram o nível socioeconômico dos participantes. Cabe ressaltar que alguns estudos abrangeram mais de um nível socioeconômico em sua amostra.

No que se refere aos participantes dos 14 estudos empíricos, a maioria investigou os progenitores (oito estudos) e familiares ou responsáveis (cinco estudos), seguidos de professores (cinco estudos) e profissionais da educação - como diretores, bibliotecários, funcionários da escola - (quatro estudos). Ressalta-se que quando os participantes foram progenitores ou familiares responsáveis, a presença feminina sobrepujava a masculina, ou seja, mães, avós e cuidadoras responsáveis se prontificaram mais a participar destas investigações do que pais, avôs e cuidadores. Também com relação aos sujeitos participantes, cabe a ressalva de que alguns estudos pesquisaram progenitores e professores no mesmo trabalho.

Os instrumentos mais utilizados nas pesquisas empíricas foram as entrevistas, descritas como abertas, semiestruturadas ou semidirigidas (seis estudos) ou estruturadas e dirigidas (dois estudos). Seguiram-se a estes instrumentos, as observações (três estudos) e observações participantes (dois estudos), análise documental (dois estudos), registros ou diários de campo (três estudos) e os questionários (dois estudos). Cabe salientar que outras designações de instrumentos também puderam ser verificadas, como "questionário abrangente", "entrevistas informais", "busca bibliográfica", aparecendo nos artigos como sendo os instrumentos utilizados para coleta de dados. Mais uma vez é importante ressaltar que alguns estudos utilizaram-se de mais de um instrumento para coleta das informações.

Com relação aos tipos de análises, percebe-se que nos 14 artigos empíricos a Análise de Conteúdo (AC) foi a mais utilizada, sendo claramente mencionada em quatro artigos. Em outros cinco, infere-se que a AC foi a escolha adotada, não sendo explícito na descrição. Três trabalhos explicam de forma insuficiente o tratamento das informações coletadas, não mencionando o procedimento de análise específico. Um trabalho utilizou o Estudo de Caso. O único artigo de pesquisa quantitativo utilizou análise estatística - Mann-Whitney e Wilcoxon - para checar as diferenças na proficiência em leitura de crianças antes e depois da participação dos pais em um procedimento sugerido pela escola para melhorar seu desempenho.
Por fim, um ponto de importante consideração se refere às contribuições dadas pelos trabalhos. Dos 31 artigos, 22 apresentaram uma sessão de Conclusão ou Considerações Finais, os demais não apresentaram claramente descritas suas conclusões. Cabe ressaltar que, dentre aqueles que explicitaram conclusões, alguns o fizeram de maneira mais breve ou genérica, não retomando a ideia principal mediante uma articulação entre a introdução e os argumentos apresentados no desenvolvimento do texto.

\section{Eixo II - Teorias}

A leitura criteriosa da coleção de 31 artigos evidenciou o que Nogueira, Romanelli e Zago (2011) já haviam apontado: há diversas tendências teórico-metodológicas que abordam a relação entre famílias e escola no Brasil, sendo que muitos autores recorrem à Sociologia e à Sociologia da Educação para compreender o fenômeno. Citando autores como Pierre Bourdieu, Joyce Epstein e Annette Lareau, muitos artigos buscaram examinar aspectos culturais e sociais desta relação, enfatizando estudos de arranjos familiares de crianças de camadas populares, ou provenientes de outros grupos étnicos, e o impacto destes na realidade escolar. O autor Philippe Perrenoud também foi bastante citado, especialmente para discutir aspectos relacionados às relações entre docentes e escolas.

A Teoria Sistêmica e a perspectiva Sócio-histórica iluminam as tentativas de explicação para as transformações da família e as implicações na interação com as escolas. A perspectiva Bioecológica de Urie Bronfenbrenner é, muitas vezes, associada a outras abordagens teóricas para explicar o contexto e a dinâmica dos sistemas em que escola e família se unem ou se separam.

\section{Eixo III - Temáticas}

\section{a) A importância de boas relações entre família e escola}

A parte introdutória da maioria dos artigos (COSTA, 2012; MARCONDES e SIGOLO, 2012; OLIVEIRA e MARINHO-ARAUJO, 2010; SILVEIRA e WAGNER, 2009; DESSEN e POLONIA, 2007; MARTURANO, 2006; POLONIA e DESSEN, 2005; GLÓRIA, 2005; MAIMONI e BORTONE, 2001; BHERING e SIRAJBLATCHFORD, 1999; SZYMANSKI, 1997) trata da importância da boa comunicação entre família e escola para beneficiar as conquistas acadêmicas e o sucesso do educando, considerando que ambas possuem objetivos comuns, sendo a família responsável pela socialização primária e a escola pela socialização secundária dos jovens (GUZZO, 1990). O envolvimento dos pais ou responsáveis é importante não apenas para a melhoria do processo escolar do aluno, mas, também, para a melhoria 
do ambiente familiar, influenciando positivamente o curso do desenvolvimento da criança (MAIMONI, 1998; GUZZO, 1990). Alguns textos salientam que ambas as instituições podem atuar como propulsoras ou inibidoras do desenvolvimento físico, intelectual, emocional e social do sujeito. Ainda que o momento atual revele interesse crescente dos pesquisadores pelo tema, Marturano (2006) ressalta que faltam instrumentos que tenham a finalidade específica de identificar, no âmbito das famílias, recursos promotores do desenvolvimento escolar.

\section{b) Famílias}

Inúmeros artigos abordam definições de família na atualidade e discutem se esta vem vivendo ou não uma crise em sua forma de se estruturar, devido às suas novas configurações (MARCONDES e SIGOLO, 2012; OLIVEIRA e MARINHO-ARAÚJO, 2010; SILVEIRA e WAGNER, 2009; POLONIA e DESSEN, 2007; SILVA, 2007; GLÓRIA, 2005; CARVALHO, 2004; NUNES e VILARINHO, 2001; CARVALHO, 2000; BHERING e SIRAJ-BLATCHFORD, 1999; WOLF, 1989). Apesar da busca por um conceito comum ser recorrente na literatura, Oliveira e Marinho-Araújo (2010) referem ainda não ser possível afirmar que exista uma definição única, aceita consensualmente. Mesmo assim, há que se privilegiar àquelas definições que contemplam as variáveis mínimas do que se entende por família: a existência de uma díade, formada por adultos, e a intimidade vivenciada por seus membros.

$\mathrm{Na}$ atualidade, conforme apontam Nunes e Vilarinho (2001), existem inúmeras possibilidades de famílias, o que não comporta mais o modelo de configuração tradicional e nuclear, pois os papéis se modificaram, bem como as obrigações e expectativas em decorrência dos avanços sociais, tecnológicos e econômicos afetando diretamente sua elaboração do conhecimento e formas de interação cotidiana (DESSEN e POLONIA, 2007; BHERING e SIRAJ-BLATCHFORD, 1999). Isto repercute na educação dos filhos e reflete, assim, nas relações desenvolvidas com a escola dos mesmos (NUNES e VILARINHO, 2001). A repercussão social de ter um filho em uma família nuclear, monoparental ou recomposta, segundo Glória (2005) não é a mesma e criam-se expectativas diferentes, dentre as quais àquelas relativas aos processos de construção daescolaridade.

Os textos ressaltam que muitas escolas seguem não conseguindo se aproximar das famílias e persistem afirmando seu domínio sobre o saber, a partir da crença da omissão dos progenitores na educação dos filhos (SILVEIRA e WAGNER, 2009; CARVALHO, 2004; CARVALHO, 2000; WOLF, 1989). Através de uma ótica um tanto unidirecional, que imputa aos responsáveis boa parte da responsabilidade pelas dificuldades de aprendizagem das crianças e adolescentes, as famílias, sobretudo as de configurações não nucleares, são percebidas como desinteressadas, ausentes e negligentes com relação à escolarização de seus filhos (MARCONDES e SIGOLO, 2012; SILVA, 2007; NOGUEIRA, 1998; CUNHA, 1996; WOLF, 1989).

A escola, na opinião de Nunes e Vilarinho (2001), precisa estar preparada para atender às famílias em suas novas configurações e, também, à família ampliada e "cotidiana" de cada aluno, como, por exemplo, no caso de avós que assumem os cuidados diários dos netos em função do trabalho dos filhos ou de eventuais rompimentos de relacionamentos. Para que a relação família-escola esteja fundamentada em pressupostos de igualdade, é preciso haver mudanças nas relações já tradicionalmente construídas (MARCONDES e SIGOLO, 2012).

\section{c) Envolvimento}

A grande maioria dos artigos analisados discute a importância e as dificuldades em se definir o envolvimento das famílias com a escola, muitas vezes desde os primórdios desta relação (NOGUEIRA, 1998; CUNHA, 1996). Alguns autores salientam que o envolvimento dos progenitores tem efeitos positivos na vida acadêmica dos filhos, pois através do auxílio e interação na realização das tarefas de casa, encorajamento verbal e reforço de comportamentos desejados, monitoramento das atividades diárias e participação em reuniões, discussões e atividades escolares, os pais contribuem para o melhor aproveitamento e sucesso acadêmico das crianças e jovens (SOARES, SOUZA e MARINHO, 2004; GUZZO, 1990). Outros artigos (MAIMONI e BERTONE, 2001; MAIMONI, 1998) citam a falta de consenso sobre a definição de 'envolvimento' e lançam luz sobre as dificuldades de avaliá-lo, especialmente se considerarmos dois aspectos: 1) quem será o avaliador (Pais? Professores? Alunos?) - isto implicará em diferentes pontos de vista sobre o fenômeno; 2) qual melhor instrumento para pesquisar o envolvimento dos pais na escolarização dos seus filhos (Entrevistas? Questionários? Observações? Escalas?). Para superar as descontinuidades entre família e escola no que tange a este aspecto, Polonia e Dessen (2005) apontam que é preciso conceber a existência de diferentes formas de envolvimento entre pais e escola, pois só assim será possível estabelecer objetivos comuns e contar com a parceria deles.

Os professores, segundo Marcondes e Sigolo (2012), entendem o envolvimento dos pais como sendo necessário para auxiliar nas tarefas de casa e acham importante a presença dos mesmos em reuniões e eventos festivos (GOMES,1993), nos quais auxiliam com donativos ou com seu trabalho. Outros autores apontam que os 
pais entendem envolvimento a partir da sua ajuda na organização do cotidiano dos filhos, auxílio nas tarefas de casa, apoio às iniciativas da escola e o favorecimento de condições para o desenvolvimento dos estudos (IUNES, SILVA, MONTENEGRO et al., 2010; GOMES, 1993). As famílias gostariam de ocupar espaços decisórios na escola (RIBEIRO e ANDRADE, 2006), ou serem mais convidadas para participar de eventos culturais, para troca de experiências (IUNES, SILVA, MONTENEGRO et al., 2010).

Os artigos constatam que os professores desejam maior envolvimento dos progenitores em situações onde percebem alguma dificuldade, e se sentem impotentes para lidar com os alunos; em situações disciplinares e de baixo rendimento acadêmico; em situações em se faz necessário algum tipo de acompanhamento profissional extraclasse (CARVALHO, 2004b; GOMES, 1993). Alguns autores chamam a atenção para o fato da escola frequentemente delegar orientações e terceirizar soluções, a partir de encaminhamentos das famílias a outros profissionais, não se comprometendo com um envolvimento maior e se furtando de assumir novas atitudes em parceria com as famílias (SILVEIRA e WAGNER, 2009; FEVORINI e LOMÔNACO, 2009; WOLF, 1989). É justamente nos casos de dificuldades que os pais tendem a querer participar mais para ajudar a solucionar o problema (MARTURANO, 2006). Guzzo (1990), por outro lado, aponta que inúmeras famílias delegam cada vez mais às escolas a tarefa de formação dos filhos e esperam respostas aos seus problemas, sem se disponibilizarem, no entanto, a estabelecer contatos mais planejados com os filhos, a fim de garantir vínculos que estimulem o desenvolvimento intelectual e levem à resolução de conflitos. Esperam, assim, que a escola resolva as dificuldades dos filhos, sem que necessite do seu envolvimento.

Os artigos também ressaltam que os pais se preocupam e valorizam o acompanhamento escolar dos filhos, independente do seu nível socioeconômico e de escolaridade, embora, muitas vezes, sintam dificuldades em fazê-lo (DESSEN e POLONIA, 2007; RIBEIRO e ANDRADE, 2006), pois: precisam de mais orientações da escola sobre como ajudar seus filhos frente às dificuldades escolares (CHECHIA e ANDRADE, 2005); desconhecem os assuntos trabalhados na escola e o nível de dificuldade de aprendizagem do filho; desconhecem os tipos de avaliação feitas pela escola e não sabem como proceder para enfrentar tais aspectos (SOARES, SOUZA e MARINHO, 2004; WOLF,1989). Alguns artigos demonstram que os pais podem sentir que seu envolvimento na escola pode prejudicar a independência dos filhos (BHERING e SIRAJ-BLATCHFORD, 1999), ou que sua contribuição não acrescentará muito ao ambiente de ensino, pois percebem seu conhecimento como inadequado ou inferior ao transmitido pela escola (POLONIA e DESSEN, 2005).

Os estudos demonstram que a escola deve compreender as inúmeras formas dos pais se envolverem com a aprendizagem de seus filhos (CARVALHO, 2004b; BHERING e SIRAJ-BLATCHFORD, 1999), considerando sempre as diferenças de classe, sexo e gênero (CARVALHO, 2004b), estrutura e tradição de escolarização, meio urbano ou rural, número de filhos, ocupação dos pais, entre outras (FARIA FILHO, 2000). É fato, no entanto, que o envolvimento ou não da família não depende da sua configuração, conforme apontam os estudos de Marcondes e Sigolo (2012) e Fevorini e Lomônaco, (2009).

\section{d) Formas de Comunicação}

De modo geral, a comunicação entre escolas e famílias é relatada nos artigos como sendo prioritariamente exercida nas formas tradicionais, isso é: bilhetes em cadernos ou agendas, conversas breves na entrada ou na saída da escola, encontros em datas comemorativas e a partir do principal canal de comunicação: as reuniões de pais (MARCONDES e SIGOLO, 2012; OLIVEIRA e MARINHO-ARAÚJO, 2010; BHERING e SIRAJBLATCHFORD, 1999). Também aparece caracterizada como unidirecional e não compartilhada, ou seja, a escola comunica o que deseja dos pais enquanto estes sentem que não são ouvidos e que há pouco espaço institucional para acolher suas manifestações (OLIVEIRA e MARINHOARAÚJO, 2010; FEVORINI e LOMÔNACO, 2009). $\mathrm{O}$ que mais motiva a escola a querer se comunicar com os pais são, segundo os artigos analisados, as situações de baixo rendimento, mau comportamento ou problemas escolares (COSTA, 2012; FEVORINI e LOMÔNACO, 2009), embora o que os pais mais desejam, conforme apontado em alguns estudos, é que possam ter mais acesso às informações importantes sobre a escolaridade dos filhos e estabelecer um diálogo aberto com os professores (MUNHOZ e SCATRALHE, 2012; OLIVEIRA e MARINHO-ARAÚJO, 2010; BHERING e SIRAJ-BLATCHFORD, 1999). Os professores, por sua vez, desejam que os pais sejam mais permeáveis às suas orientações (MUNHOZ e SCATRALHE, 2012).

Conflitos na comunicação ocorrem, conforme relatado nos artigos, na medida em que a família se queixa de pouco esclarecimento e os professores se queixam das cobranças familiares (MUNHOZ e SCATRALHE, 2012). Quando uma situação de dificuldade com o aluno se apresenta, conforme referem Silveira e Wagner (2009) os professores, muitas vezes, responsabilizam a família pelos problemas da criança e a família, ao perceber isto, cobra dos professores soluções - o que acaba dificultando a comunicação entre todos. Conflitos para 
uma boa comunicação também podem surgir quando existe clara diferença de tratamento dispensada por parte dos professores a alguns pais, geralmente beneficiando aqueles de classes sociais mais abastadas (MARANHÃO e SARTI, 2008). Costa (2012) nomeia tais barreiras de in-comunicações e ressalta que estas decorrem de fatores culturais e socioeconômicos.

O estudo de Munhoz e Scatralhe (2012) propõe que haja um espaço conversacional na escola, onde se possa falar, trocar, ouvir, questionar e dialogar com os participantes que fazem parte do processo escolar do aluno (pais e professores fundamentalmente). A comunicação é apontada por Bhering e Siraj-Blatchford (1999) como fundamental para que os pais compreendam, e os professores expliquem os objetivos da escola, o desenvolvimento das crianças, o processo educacional e a atuação docente. Para que haja o estabelecimento de um diálogo efetivo, é preciso que os professores aceitem a responsabilidade de se comunicarem de forma clara, simples e compreensível com os pais, conforme apontam Polonia e Dessen (2005). Também é preciso, de acordo com Guzzo (1990) que os pais disponham de algum tempo e interesse para o diálogo, estando disponíveis para o estabelecimento de vínculos com a escola. O ponto de partida deve ser o reconhecimento mútuo destas duas instituições como sendo de grande importância para o desenvolvimento da criança, não tornando a comunicação um "diálogo de surdos", como muito frequentemente se percebe, conforme relata Szymanski (1997). Além disso, dialogar requer consciência de igualdade e certeza de respeito mútuo, o que não ocorre quando os pais estão em posição subalterna, como refere Gomes (1993), ou quando os professores ficam inibidos frente aos questionamentos de alguns pais com formação superior à sua, conforme cita Munhoz e Scatralhe (2010).

\section{e) Reuniões de pais/responsáveis}

As reuniões de pais promovidas pelas escolas foram tema recorrente nos artigos analisados (GARCIA e MACEDO, 2011; IUNES, SILVA, MONTENEGRO et al., 2010; OLIVEIRA e MARINHO-ARAÚJO, 2010; FEVORINI e LOMÔNACO, 2009; RIBEIRO e ANDRADE, 2006; NUNES e VILARINHO, 2001; BHERING e SIRAJ-BLATCHFORD, 1999; GOMES, 1993). Nestes trabalhos as reuniões de pais não foram percebidas a partir de um olhar positivo e animador por parte das famílias, e muitas apontaram sugestões para possíveis melhorias.

No estudo de Marcondes e Sigolo (2012) os progenitores criticaram as reuniões, pontuando que são superficiais, possuem comunicações unilaterais, são hierarquizadas, sem trocas, sem participação da família, sem confiança ou respeito e, sobretudo, não discutem aspectos importantes. $\mathrm{O}$ artigo de Ribeiro e Andrade (2006) aporta considerações semelhantes por parte dos progenitores pesquisados, que mencionaram que as reuniões de pais são chatas, cansativas, demoradas e não interessantes, com os assuntos versando apenas sobre mau comportamento e baixo rendimento dos alunos. Os participantes do estudo de Fevorini e Lomônaco (2009) pontuam praticamente os mesmos aspectos, acrescentando que as reuniões são monótonas e longas, normalmente monopolizadas por alguns poucos pais. Ressaltam que a ênfase quase sempre recai sobre os procedimentos e conteúdos e não nas características da turma. É interessante ressaltar que estes pais acreditam que as reuniões são importantes e, por isso, deveriam ser preparadas com mais cuidado, além de poder contar sempre com a presença dos professores, e não apenas da equipe diretiva.

$\mathrm{O}$ fato de realizarem reuniões para comunicar apenas regras, rotinas, necessidade de materiais, incomoda os progenitores participantes do estudo de Bhering e SirajBlatchford (1999), que gostariam de saber mais sobre o desenvolvimento e o processo de aprendizagem de seus filhos. O mesmo é referido pelos pais entrevistados no artigo de Iunes, Silva, Montenegro et al. (2010), que gostariam de conhecer mais os assuntos referentes ao funcionamento institucional, projetos desenvolvidos e propostas de melhorias educacionais.

Gomes, em seu artigo de 1993, ressaltou que geralmente a escola promove reuniões com a finalidade de dar explicações, para não dizer "fazer queixas" conforme refere a autora - sobre o comportamento e desempenho dos alunos. Percebe-se, assim, que a tradição de reuniões enfadonhas, longas, com comunicação de mão única e nas quais as famílias, muitas vezes, são julgadas e criticadas sem ter igual oportunidade de participação, parece ter se estabelecido desde há muito tempo.

Em seu estudo sobre a "família possível" na relação família-escola, Nunes e Vilarinho (2001) pontuam que os pais eram muitas vezes convocados para reuniões e não compareciam, o que nos mostra a importância de entender a forma como tais encontros são estruturados e por que a participação fica comprometida. Foi este o objetivo do estudo de Garcia e Macedo (2011), quando se propuseram a analisar diferentes modos de gestão de reuniões pelos professores no contexto da Educação Infantil. Através da observação de onze reuniões de pais realizadas por seis professoras diferentes em duas escolas municipais de São Paulo, os autores concluíram que: apenas uma delas foi estruturada de forma compartilhada, com pauta prévia usada como referência com flexibilidade por um professor que consultava os pais e tinha postura autônoma e criativa; apenas três possuíam conteúdos educacionais, onde o tema era o projeto pedagógico e a sustentação do mesmo 
ocorria mediante a apresentação dos trabalhos realizados com e pelos alunos; e apenas duas foram classificadas como tendo uma dinâmica coletiva, havendo, portanto, interações múltiplas entre o professor e o grupo de pais, bem como entre os pais, todos participando e cooperando entre si. As demais reuniões analisadas mostraram-se desorganizadas ou rígidas, quanto à forma; burocráticas ou comportamentais quanto ao conteúdo; e fragmentadas ou centralizadas como dinâmica de condução.

\section{f) Presença de Mães}

Diversos artigos chamam a atenção para a maior participação das mães nos assuntos relacionados à educação dos filhos e mencionam sua presença mais assídua na escola, se comparada a dos pais (FEVORINI e LOMÔNACO, 2009; CHECHIA e ANDRADE, 2005; GLORIA, 2005; CARVALHO, 2004a; CARVALHO, 2004b; CARVALHO, 2000; BHERING e SIRAJBLATCHFORD, 1999).

Artigo de Chechia e Andrade (2005) refere que são as mães que, com maior frequência, acompanham as atividades escolares dos filhos, apresentam um cuidado maior e dão mais atenção na realização das tarefas de casa, pois acreditam que os filhos necessitam de sua presença e auxílio. A presença do pai na escola ocorre, geralmente, quando o filho apresenta algum tipo de comportamento indesejável e é repreendido pela professora. O estudo de Glória (2005) vai ao encontro destas constatações, ao propor que por assumir o cuidado diário dos filhos e acompanhar seus estudos mais de perto, o papel da mãe acaba sendo efetivamente mais importante que o do pai, embora a autora discuta mais a fundo as questões de gênero nas interações entre pais, mães e filhos no que tange às expectativas e projetos educativos quanto ao futuro escolar.

A participação de mães e sua luta, principalmente nas camadas populares, por acesso e melhoria na qualidade do ensino público, são frequentes, conforme aponta estudo de Bhering e Siraj-Blatchford (1999) e suas reivindicações passam por níveis estruturais representados por associações de pais e mestres, colegiados, conselhos da escola, etc. Nesses grupos, a presença de mães é mais representativa que a de pais, tal como ocorre nas reuniões da escola (FEVORINI e LOMÔNACO, 2009). Em seus três artigos, Carvalho (2004a; 2004b; 2000) discute as implicações de gênero resultantes das relações família-escola e salienta que na política de participação e auxílio aos alunos, as mães acabam ficando sempre sobrecarregadas, principalmente quando tem que dar conta dos temas de casa junto aos filhos. Aos pais cabe, apenas, um papel mais burocrático

Os artigos analisados reiteram o que se percebe na prática, ou seja, que há maior presença feminina no que tange aos assuntos vinculados à escolarização das crianças. Da coleção de 32 artigos, doze eram relatos de pesquisa que se propuseram a entrevistar pais e mães ou responsáveis pelas crianças em seus estudos. Dentre estes doze, sete revelam informações sobre o sexo dos participantes e verificou-se, em todos estes, que a maioria eram mães ou algum cuidador responsável do sexo feminino, como as avós, por exemplo.

\section{DISCUSSÃo}

Partindo do pressuposto que o tema das relações da família com a escola é bastante amplo, complexo e, sobretudo, multi influenciado, pode-se compreender as dificuldades encontradas em pesquisa-lo. O estágio atual de pesquisas nessa área no Brasil parece ser de construção e delimitação do próprio objeto de investigação, onde algumas temáticas vem se constituindo e consolidando a partir do confronto com a realidade (NOGUEIRA, ROMANELLI e ZAGO, 2011). Os artigos analisados neste estudo parecem, em muitos aspectos, refletir a complexidade inerente à temática, assim como as metodologias disponíveis para aceder ao problema. Nessa perspectiva, alguns trabalhos também denotam a dificuldade de delimitação do objeto de pesquisa.

Sendo o fenômeno multicausal, pois sofre a influência de inúmeras variáveis, a exigência de certo rigor na descrição do método se faz necessária, a fim de que fiquem claros os passos adotados para responder aos objetivos propostos. Neste sentido, considerando-se os aspectos metodológicos dos artigos avaliados, chamou a atenção o fato de muitos não possuírem uma descrição detalhada e compreensível dos procedimentos utilizados para a realização do estudo. Ainda que alguns artigos não tenham sido resultado de investigações empíricas, é fundamental a explicitação de como se deu a busca das informações: se foi ou não uma busca sistemática, se foi um ensaio cujo objetivo era proporcionar uma reflexão de ideias, entre outras tantas possibilidades metodológicas. O cuidado na descrição rigorosa de tais procedimentos confere maior credibilidade aos estudos. Quando se trata de artigos empíricos, a situação é mais delicada ainda, pois nestes casos é imprescindível que o método, em todas as suas etapas, seja descrito de forma explicita e clara, para que o leitor possa compreender de onde se extraíram as informações sobre as quais se apresenta uma discussão e conclusões. Além da falta de credibilidade dos dados na ausência desta descrição detalhada, a pesquisa fica inviabilizada de ser replicada em outro contexto e com outros participantes, por exemplo.

Apesar de abordarem temas relevantes para a área das relações família-escola, a fragilidade metodológica observada em alguns artigos revisados acaba por 
comprometer a sua qualidade. Salienta-se a dissonância entre objetivos do estudo e a descrição dos motivos da escolha dos instrumentos. Nesses casos, apareceram estudos que não explicitavam o motivo da escolha de uma "entrevista estruturada" ou "semidirigida", por exemplo. Em alguns artigos estudados, também não foram apresentados os roteiros das entrevistas. Assim, o uso de entrevistas, bem como métodos de observação e análise de documentos, muitas vezes não se justificavam e sequer eram retomados, posteriormente, na seção de resultados e discussão. Ocorria, portanto, em algumas situações, entrevistas com sujeitos cujo depoimento não era descrito ou mencionado na discussão. A não utilização dos dados coletados pelo pesquisador vai de encontro ao estabelecimento dos padrões éticos previstos para pesquisas envolvendo seres humanos, pois onera o participante, sem necessidade. A ausência de certo rigor metodológico no campo da pesquisa em educação já fora apontada por diversos autores (BRANDÃO, 2011; LAROCCA, ROSSO e SOUZA, 2005; ALVEZMAZOTTI, 2001; ANDRÉ, 2001) que referiram problemas na produção científica da área em aspectos como rigor, relevância, identidade, implicações e perspectivas da pesquisa educacional, além da necessidade de se produzir um corpo de conhecimento mais sólido e confiável - tanto teórico como metodologicamente - e sistematizar a forma de comunicação das produções.

Também é digno de nota a constatação de que dos 32 artigos estudados a sessão de Considerações Finais, ou Conclusões, não estava presente em oito. Muitos, ainda, apresentavam conclusões genéricas, que não aprofundavam ou avançavam com relação ao tema das relações família-escola. Percebe-se, portanto, que a complexidade do tema gera dificuldades em sua abordagem e, muitas vezes, os artigos, ainda que compostos por ampla e interessante revisão de literatura, não problematizam e discutem seus achados.

Por fim, ressalta-se, com relação à avaliação metodológica dos artigos, que se faz necessária a adoção de critérios rigorosos de avaliação dos artigos por parte dos periódicos da área. Todos eles estavam publicados em revistas indexadas e bem avaliadas pelo Qualis Periódicos (CAPES), o que nos remete à necessidade da existência de um crivo mais exigente, que possa contribuir com a garantia de rigor e qualidade nos estudos. Quanto melhor classificado o periódico, maiores devem ser as exigências a serem cumpridas.

No que se refere à análise das teorias e temáticas abordadas nos artigos, é possível perceber que a maioria deles, em sua parte introdutória, faz algum tipo de consideração ou menção às modificações que ocorreram na configuração das famílias e as mudanças que estas acarretaram nos papéis sociais desempenhados por família e escola ao longo das últimas décadas. Também mencionam que, na atualidade, existe grande incentivo a uma relação mais próxima e de parceria entre estas duas instituições, embora nem sempre isso seja fácil de se concretizar na prática. Apontamentos quanto às funções e responsabilidades dos pais e professores são descritos, ora sendo percebidos como tendo objetivos diferentes, ora referidos como complementares, ora como sequenciais (onde a escola, na figura do professor, deve seguir o trabalho educativo até então desempenhado unicamente pelas famílias). Entretanto, não parece haver tentativas de propostas sobre como realizar a aproximação destes dois contextos na prática. Assim, muitos artigos acabam sendo finalizados de forma um tanto filosófica e idealística, com conclusões que mencionam apenas o quanto seria importante realizar ações que permitissem à família se aproximar e se apropriar mais do espaço escolar, ou o quanto é importante que se criem novos canais de comunicação entre escola e família. No entanto, não há proposições concretas de ações que contribuam neste sentido.

Assim, a literatura brasileira em seu panorama atual parece refletir um primeiro momento, que remete ao diagnóstico das dificuldades na relação entre escola e família, com foco naqueles aspectos que não estão funcionando e não favorecem uma parceria satisfatória. Percebe-se intenso debate sobre uma série de aspectos que merecem maior atenção e precisam ser aprimorados, como a comunicação entre estes dois sistemas, os tipos de envolvimento que podem ser estimulados, as formas de participação de famílias com diferentes configurações familiares, entre outros. O grande desafio que se faz presente em nosso país talvez seja, justamente, o de avançar com relação a este primeiro momento de diagnóstico de dificuldades para outro patamar, cujo foco seja pensar estratégias de intervenção, construção de instrumentos validados para nossa realidade e alternativas de trabalho que deem conta de otimizar a relação entre escola e família, docentes e pais ou responsáveis, migrando do "o quê é difícil" para o "como transformar" tal situação.

Ainda estamos dando os primeiros passos no que se refere à proposição de alternativas práticas que resultem em aprimoramento da parceria família e escola, especialmente se nos compararmos a outros contextos, onde trabalhos desenvolvidos já estão a muito tempo consolidados, como nos Estados Unidos, por exemplo, com os estudos e projetos de intervenção elaborados pelo National Network of Partnership Schools, na School of Education da Johns Hopkins University, liderados pela Dra. Joyce Epstein. Embora algumas iniciativas possam ser constatadas em nosso contexto (WAGNER, TORNARÍA GONZÁLEZ, SARAIVA JUNGES et al., 2014), carecemos ainda de instrumentos que pesquisem 
opiniões de professores, famílias e alunos quanto à forma como exercem esta parceria - e materiais de intervenção adequados à nossa realidade que abordem a formação docente para trabalhar com as famílias; a formação da escola para auxiliar seu corpo de professores a aprimorar esta relação; e estratégias de parceria efetivas, que permitam a participação de todas as famílias das mais diversas formas possíveis.

\section{CONCLUSÕES}

A produção científica sobre a Relação Família-Escola no Brasil ainda demonstra certa fragilidade metodológica, remetendo, muitas vezes, a conclusões genéricas, que não aprofundam ou avançam com relação ao tema. Tal fragilidade parece estar relacionada ao momento atual das pesquisas sobre a temática no Brasil, que abordam, sobretudo, um diagnóstico de dificuldades e constatações da necessidade de propostas de intervenção para otimização desta parceria. Entretanto, ainda não se percebem avanços com relação a proposições práticas que tenham por objetivo trabalhar em prol de uma parceria efetiva entre escola e famílias. É preciso passar do patamar das constatações e queixas para outro de proposições e prospecções, que inovem e consolidem estratégias para o estabelecimento de parcerias de trabalho entre estes dois sistemas em nosso contexto. Assim, o conhecimento até então construído nas pesquisas brasileiras sobre a temática poderá avançar do limite que reconhece e demonstra a importância da parceria família-escola, para apontar caminhos e propor alternativas, auxiliando, de fato, no dia a dia desta relação e contribuindo para a promoção de saúde no espaço escolar. Eis o grande desafio atual!

\section{REFERÊNCIAS}

ALVEZ-MAZZOTTI, Alda Judith. Relevância e Aplicabilidade da Pesquisa em Educação. Cadernos de Pesquisa, São Paulo, n. 113 , p. $39-50$, jul. 2001.

ANDRÉ, Marli. Pesquisa em Educação: buscando rigor e qualidade. Cadernos de Pesquisa, São Paulo, n. 113, p. 51-64, jul. 2001

BHERING, Eliana; SIRAJ-BLATCHFORD, Iram. A relação escola-pais: um modelo de trocas e colaboração. Cadernos de Pesquisa, São Paulo, n. 106, p. 191-216, mar. 1999.

CARVALHO, Maria Eulina Pessoa de. Relações entre Família e Escola e suas implicações de Gênero. Cadernos de Pesquisa, São Paulo, n. 110, p. 143-155, jul. 2000.

CARVALHO, Maria Eulina Pessoa de. Escola como extensão da família ou família como extensão da escola? O dever de casa e as relações família-escola. Revista Brasileira de Educação, Rio de Janeiro, n. 25, p. 94-104, jan./abr. 2004a.

CARVALHO, Maria Eulina Pessoa. Modos de Educação, Gênero e Relações Escola-Família, Cadernos de Pesquisa, São Paulo, v. 34, n. 121, p. 41-58, jan./abr. 2004b.
CAVALCANTE, Roseli Schultz Chiovitti. Colaboração entre pais e escola: educação abrangente. Psicologia Escolar e Educacional, Campinas, v. 2, n. 2, p. 153-160, 1998. https:// doi.org/10.1590/S1413-85571998000200009

CHECHIA, Valéria Aparecida; ANDRADE, Antônio dos Santos. O desempenho escolar dos filhos na percepção de pais de alunos com sucesso e insucesso escolar. Estudos de Psicologia, Natal [online], v. 10, n. 3, p. 431-440, 2005. https:// doi.org/10.1590/S1413-294X2005000300012

COSTA, Graça dos Santos. Famílias Imigrantes e Escolas em Barcelona: expectativas e realidades. Revista Interdisciplinar de Mobilidade Humana, Brasília, ano XX, n. 38, p. 141-162, jan./jun. 2012.

CUNHA, Marcus Vinícius da. A Escola Renovada e a Família Desqualificada: do discurso Histórico-Sociológico ao Psicologismo na Educação. Revista Brasileira de Estudos Pedagógicos, Brasília, v. 77, n. 186, p. 318-345, maio/ago. 1996.

DESSEN, Maria Auxiliadora; POLONIA, Ana da Costa. A família e a escola como contextos de desenvolvimento humano. Paidéia, Ribeirão Preto, v. 17, n. 36, p. 21-32, 2007.

EPSTEIN, Joyce L. School, Family, and Community Partnerships: preparing educators and improving schools. Baltimore, Johns Hopkins University: Westview Press, 2011.

EPSTEIN, Joyce., et al. School, Family and Community Partnerships, Your Handbook for Action. 2. ed. Corwin Press, 2009

FARIA FILHO, Luciano Mendes de. Para entender a Relação Escola-Família: uma contribuição da história da educação. São Paulo em Perspectiva, São Paulo, v. 14, n. 2, p. 44-50, abr./ jun. 2000. https://doi.org/10.1590/S0102-88392000000200007

FÁVERO, Osmar. Reseña de "Avaliação e perspectivas na área de educação: 1982-1991". Revista Brasileira de Educação, Rio de Janeiro, n. 30, p. 179-180, set./dez. 2005.

FEVORINI, Luciana Bittencourt; LOMÔNACO, José Fernando Bitencourt. O envolvimento da família na educação escolar dos filhos: um estudo exploratório com pais das camadas médias. Psicologia da Educação, São Paulo, n. 28, p. 73-89, jan./jun. 2009

GARCIA, Heloísa Helena Genovese de Oliveira; MACEDO, Lino de. Reuniões de Pais na Educação Infantil: Modos de gestão. Cadernos de Pesquisa [Online], v. 41, n. 142, p. 208227, jan./abr. 2011.

GLÓRIA, Dília Maria Andrade. Relação entre escolaridade e diferenças constitutivas das fratrias. Paidéia, Ribeirão Preto), v. 15, n. 30, p. 31-42, 2005.

GOMES, Jerusa Vieira. Relações família e escola: continuidade/ descontinuidade no processo educativo. Ideias, São Paulo, n. 16, p. $84-92,1993$.

GUZZO, Raquel Souza Lobo. A família e a educação: uma perspectiva da interação família-escola. Estudos de Psicologia, v. 7, n. 1, p. 134-139, 1990.

IUNES, Silvana Maria Silva; SILVA, Aictyr Lomonte da; MONTENEGRO, Maria Eleusa; SALVIANO, Ana Regina Melo; BATISTA, Márcia Marins; PINTO, Celeida. B. Garcia. Cintra; MELO, Mariana Dantas Guimarães. Os pais e suas expectativas em relação à educação infantil da escola particular. Psicologia da Educação, São Paulo, n. 30, p. 113-126, jan./ jun. 2010 . 
KOUTROUBA, Konstantina; ANTONOPOULOU, Ekaterine; TSITSAS, Georgios; ZENAKOU, Eleni. An Investigation of Greek Teachers' Views on Parental Involvement in Education. School Psychology International, v. 30, n. 3, p. 311-328, 2009. https://doi.org/10.1177/0143034309106497

LAROCCA, Priscila; ROSSO, Ademir José; SOUZA, Audrey Pietrobelli de. A formulação dos objetivos de pesquisa na pósgraduação em Educação: uma discussão necessária. Revista Brasileira de Pós-Graduação, Brasília, v. 2, n. 3, p. 118-133, mar. 2005.

MAIMONI, Eulália Henriques. Envolvimento de pais na vida escolar do aluno - problemas de definição de medida. Revista da Sociedade de Psicologia do Triângulo Mineiro, v. 1, n. 1, p. 15-18, 1998.

MAIMONI, Eulália Henriques; BORTONE, Márcia E. Colaboração família-escola em um procedimento de leitura para alunos de séries iniciais. Psicologia Escolar e Educacional, v. 5, n. 1, p. 37-48, 2001. https://doi.org/10.1590/S1413-85572 001000100005

MARANHÃO, Damaris Gomes; SARTI, Cynthia Andersen. Creche e Família: uma parceria necessária. Cadernos de Pesquisa Online, v. 38, n. 133, p. 171-194, jan./abr. 2008. https://doi.org/10.1590/S0100-15742008000100008

MARCONDES, Keila Hellen Barbato; SIGOLO, Silvia Regina Ricco Lucato. Comunicação e envolvimento: possibilidades de interconexões entre família-escola?. Paidéia, Ribeirão Preto, v. 22, n. 51, p. 91-99, abr. 2012. https://doi.org/10.1590/S0103863X2012000100011

MARTURANO, Edna Maria. O inventário de recursos do ambiente familiar. Psicologia: Reflexão e Crítica, Porto Alegre, v. 19, n. 3, p. 498-506, 2006. https://doi.org/10.1590/ S0102-79722006000300019

MUNHOZ, Maria Luiza Puglisi; SCATRALHE, Marli da Costa Ramos. Família e escola na compreensão dos significados do processo escolar. Revista de Psicopedagogia, v. 29, n. 88, p. 55-65, abr. 2012.

*NOGUEIRA, Maria Alice. Relação Família-Escola: novo objeto na sociologia da educação. Paidéia, Ribeirão Preto, v. 8, n. 14-15, p. 91-103, 1998.

NOGUEIRA, Maria Alice; ROMANELLI, Geraldo; ZAGO, Nadir. Família \& escola: trajetórias de escolarização em camadas médias e populares. Petrópolis: Vozes, 2011.

NUNES, Dulce Gomes; VILARINHO, Lúcia Regina Goulart (2001). Família possível na relação escola-comunidade.
Psicologia Escolar e Educacional [online], v. 5, n. 2, p. 21-29, 2001. https://doi.org/10.1590/S1413-85572001000200003

OLIVEIRA, Cynthia Bisinoto Evangelista; MARINHOARAÚJO, Cleisy Maria. A relação família-escola: intersecções e desafios. Estudos de Psicologia, Campinas, v. 27, n. 1, p. 99-108, jan./mar. 2010. https://doi.org/10.1590/S0103166X2010000100012

POLONIA, Ana. da Costa; DESSEN, Maria Auxiliadora. Em busca de uma compreensão das Relações entre Família e Escola. Psicologia Escolar e Educacional, Maringá, v. 9, n. 2, p. 303 312, 2005. https://doi.org/10.1590/S1413-85572005000200012 RIBEIRO, Daniela de Figueiredo; ANDRADE, Antônio dos Santos. A assimetria na relação entre família e escola pública. Paidéia, Ribeirão Preto, v. 16, n. 35, p. 385-394, 2006. https:// doi.org/10.1590/S0103-863X2006000300009

SILVA, Graziela Lucchesi Rosa da. Psicologia educacional e arte literária: interlocuções para a compreensão dos laços familiares e escolares na atualidade. Psicologia da Educação [online], n. 24, p. 137-151, 2007.

SILVEIRA, Luíza Maria de Oliveira Braga; WAGNER, Adriana. Relação família-escola: práticas educativas utilizadas por pais e professores. Psicologia Escolar e Educacional, Maringá, v. 13, n. 2, p. 283-291, jul./dez. 2009. https://doi.org/10.1590/S141385572009000200011

SOARES, Maria Rita Zoéga; SOUZA, Sílvia Regina de; MARINHO, Maria Luíza. Envolvimento dos Pais: Incentivo à habilidade de estudo em crianças. Estudos de Psicologia, Campinas, v. 21, n. 3, p. 253-260, set./dez. 2004. https://doi. org/10.1590/S0103-166X2004000300009

SZYMANSKI, Heloísa. Encontros e desencontros na relação família-escola. Ideias, n. 28, p. 213-225, 1997.

WAGNER, Adriana; TORNARÍA GONZÁLEZ, Maria del Luján; SARAIVA JUNGES, Lisiane Alvim; HERNANDÉZ, Esthella. Os professores frente às demandas das famílias: aproximando contextos. 2014 (submetido à publicação).

WOLF, S. M. R. A escola e sua contradição com a experiência de vida da criança e de sua família. Perfil: Boletim de Psicologia, v. 2, n. 2, p. 67-97, 1989.

$\mathrm{XU}$, Fianzhong. Do early adolescents want family involvement in their education? Hearing voices from those who matter most. The School Community Journal, 2002.

Submetido em 13/07/2015

Aprovado em 13/04/2016 